\title{
Inclusive education in practice: socialisation of former combatants into society
}

\author{
Luis J. Serrano-Tamayo ${ }^{1}$, Juan D. Enciso- Congote ${ }^{2}$, Maria C. Bulla-Calero ${ }^{3}$, Lorena \\ Santodomingo-Mendoza ${ }^{4}$ \\ ${ }^{1}$ Escuela Naval Almirante Padilla, Colombia, Department of Naval Sciences, \\ ${ }^{2}$ Universidad de La Sabana, Colombia, Department of Education, \\ ${ }^{3}$ Universidad de La Sabana, Colombia, Department of Education, \\ ${ }^{4}$ Universidad de La Sabana, Colombia, Department of Education,
}

\begin{abstract}
Inclusive education has become a key issue in educational policy worldwide, however most of research has been oriented to study less privileged groups in terms of disabilities, gender, race, or language, all of them with an implicit legitimacy to be included. This paper expands the concept of inclusive education as it focuses on the socialisation process of former combatants operating outside the law. This case study explains how educational and labour duties oriented to farmers have been applied for including former combatants from the Colombian armed conflict into productive projects at Panaca, a family-oriented theme park that shows the importance of countryside for life in the cities through educational and playful activities. A series of open-ended and semi-structured interviews allowed the identification of four inclusive education manifestations: socialisation, literacy, formalities within social processes, and solidarity. The perspective of social pedagogy, which studies social dynamics of formative processes and learning processes in quotidian contexts, suggests that non-modification of organisational normative structure is needed for inclusion as well as highlights the decisive role of teachers for inclusion success. Other key factors that contributed to inclusion were the identified similarities between the organisation and the group included as well as the support from the management team.
\end{abstract}

Keywords: inclusion; inclusive education; socialisation; peace building; Colombia

\section{Introduction}

The idea of inclusive education has been pervasive in the last decades. Since its emergence from American disabilities policies in the 1990s (Ferdman, 2014) and the agreement of international community through the UNESCO Salamanca Statement (UNESCO, 1994), the idea of inclusive education fosters that political and educational institutions are those that need to change (Mittler, 2007), more than those in need to be included (Dobusch et al., 2017). For example, there is a consensus in the need of more funding for special education needs (OECD, 2003) and there is a natural link between positive attitudes to inclusive education and the funding attached to those policies (Cole, 2005). 
By the beginning of the twenty-first century, inclusive education included not only those with some physical disabilities or those with special needs, but a wider population that do not even attend school such as working children, rural dwellers and nomads, minorities both ethnic and linguistic, and children affected by conflict situations (UNESCO, 2000).

There are substantial differences if inclusive education regards to developed or developing countries, based on their culture and history (Savolainen et al., 2012). On the one hand, in developed countries research focuses on aspects such as partnerships between special and regular schools (Frederickson et al., 2004), inclusive forms of pedagogy (Florian \& Linklater, 2010) and attitudes of teachers towards inclusion initiatives (Srivastava et al., 2015). Likewise, in China, the country with the largest population with disabilities in the world, inclusive education focuses on teacher education in terms of skills and compassion, based on their tradition and culture (Wang \& $\mathrm{Mu}, 2014$ ). On the other hand, in developing countries, and in low-income countries inclusive education have much more struggles. In India, inclusive education associates to take children from factories to schools; children are preferred than adults in factories in terms of low wages, ease of discipline and physical features, although it deprives children from education and recreation (Siddiqui, 2007; McConkey \& Bradley, 2010). Worse is the case of street children who escape from reality and hunger through alcohol and several chemical drugs causing them irreversible damages, becoming part of criminal industries such as thefts, prostitution and drug trafficking (Siddiqui, 2007). Our case focuses on other population that need attention and inclusive education, individuals that have passed their life among conflict.

Research about inclusive education and conflict distinguishes three types of children. The first category is children affected by armed conflicts, i.e. those children pushed into conflict by poverty, loss of parents or forced recruitment, used as cooks, informers or soldiers. The second category is children in conflict with the law, those are mostly teenagers between 14-18 years that remain in prison. The third category includes refugees and internally displaced children (Karangwa, 2006). These children has no access to school as they are victims from conflict situations. However, the focus of literature has remained on children, people who should be studying and should have the main role of students (Lako et al., 2010). Therefore, this paper extends the concept of inclusive education by considering adult people that come from disadvantaged situations such as internal conflict. These people spent their childhood as victims of conflict and currently are more in an age for working than in an age for studying, but as they have spent all their live among conflict, they do not know any other reality and have had limited or no access to formal education. Consequently, this paper shows how inclusive education may be applied to adults that have spent their life among conflict.

This paper analyses inclusive education in practice through the socialisation of former combatants into society having account the recent case of the peace process in Colombia. The case study focuses on Panaca, a family-oriented theme park that shows the importance of countryside for the life in cities. A series of open-ended and semi-structured interviews contributed to unpack some manifestations of inclusive education that facilitated the socialisation process of people that did not pass through formal education. 
This research contributes, not only to organisations interested in the inclusion of former combatants into society, but to multiple governments and organisations interested to include the millions that come from disadvantaged situations, which have remained out of formal education. In consequence, the purpose of this paper is to illustrate how inclusive education manifested in practice into the case of former combatants that are struggling to reintegrate into society. The first objective is to clarify why this case might contribute to include disadvantaged and excluded groups, particularly those that have been involved in criminal activities; the second objective is to depict how this inclusive education process happens in practice; and third, what are the organisational and individual key factors that facilitates effective inclusion in society.

\section{Literature Review}

\subsection{Initial approach to inclusion from social sciences}

Inclusion has experienced a growing interest in research on multiple areas of knowledge. A search of the term "inclusion" on February 2018, in the title of the publication, showed a constant increasing number of academic publications, as it is presented in Figure 1. It is particularly interesting the exponential interest of inclusion at the end of the twentieth century and along the twentieth-first.

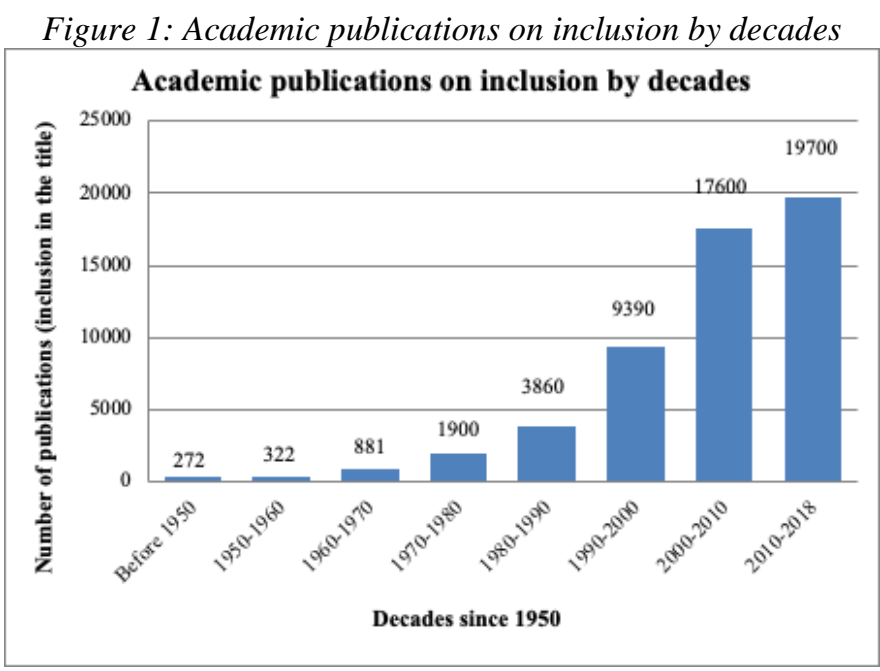

Source: Authors

Identifying a definition for inclusion has proved to be elusive. Inclusion "is a somewhat nebulous term, open to a variety of meanings and interpretations within a multitude of contexts" (Cole 2005, p. 287). Gurung (2006) problematizes inclusion, describing how political inequities, corruption, and education inequality are consequences of a lack of inclusion in society. To confront such scarce levels of inclusion, which is also known as exclusion, scholars agree on a necessary intervention from the state and population (Hunold, 2005). Consequently, inclusion has been studied in various disciplines such as education, anthropology, psychology, 
management, and sociology (Farndale et al., 2015).

On the one hand, Gurung (2006) suggests that state inclusion policies should elevate the situation of disadvantaged groups and have a distributed representation of power. For example, the state intervention in the development of infrastructure for people with disabilities in the UK is considered as a symbol of social inclusion and community cohesion (Landorf, 2011). In terms of relations between government and civil society organizations, Hunold (2005) distinguishes between active inclusion and passive inclusion. The author considers active inclusion as a "reinforced culture of consultation and dialogue" (p. 332) and passive inclusion as access to information and debates but with a limited influence or no influence. On the other hand, population also has a duty to develop their own inclusive initiatives, which require state support (Gurung, 2006).

Literature on inclusion in social sciences suggests a predominant dilemma and paradox: planned vs. emergent. Planned refers to the intentional actions and strategies from well-established government bodies, which come from a deep analysis and are aligned to a traditional approach of strategy in terms of mission, vision, and objectives. Emergent refers to spontaneous actions from community, less legitimate bodies, aligned to a strategy as practice approach. It is a dilemma because the idea of planned vs. emergent suggests a choice between both options. It is a paradox because planned inclusion may produce new exclusions, even in a higher degree of intensity, making intended inclusion counterproductive; while emergent inclusion could suggest that no intended actions are preferable to a planned policy. These two approaches, rather than being opposed to each other, might be complementary, and it is the planned inclusion from government policies that generate a climate for emergent initiatives from community. Thus, inclusion can be viewed as a social and dynamic process of construction, deconstruction and reconstruction of practices that, planned or emergent, tend to generate connections and longterm relations between individuals. Those practices are influenced by contexts and cultures, are focused on a variety of populations with diverse backgrounds and meanings of inclusion, and are perceived according to individual feelings.

\subsection{Inclusive education stakeholders and practices}

Education is the most prominent area of social sciences that has studied inclusion. The UNESCO 'Salamanca Statement and Framework for Action on Special Needs Education' (UNESCO, 1994) has been a reference that has fostered research on inclusive education in the last decades. Early debates have been around inclusion malleability. Ryan (1994) suggests that students with disabilities do not need to follow a standardized curricula; on the contrary, they may meet the education objectives in an individual education plan. Thus, students with disabilities can be included in mainstream schools and the mainstream curricula, but evaluated according to their particular programme. Conversely, Murphy (1996) uses the term full inclusion to define a comprehensive approach to inclusion as: "the total integration of all students who have special needs - particularly those with disabilities - into the age-appropriate, regular education classrooms of their community schools, regardless of the nature or degree of the needs involved" (p. 471). However, Murphy (1996) recognizes that this comprehensive 
definition is also unachievable, and in many cases is prejudicial to the mainstream and to the student included, particularly in cases of more severe disabilities. Thus, in order to evaluate inclusion in educational systems, Murphy (1996) suggests four debates: the relative effectiveness of inclusion programmes; the costs associated to inclusion initiatives; the complex legislation and regulations on inclusion; and implications for the stakeholders involved such as students, parents, teachers, and policy makers. Complementarily, Booth and Ainscow (2002) developed the 'index for inclusion', which has three dimensions: inclusive cultures (community construction, inclusive values), inclusive policies (a school for everyone, support to attend school diversity), and inclusive practices (learning process orchestration, resource mobilization).

The beginning of the $21^{\text {st }}$ century expanded inclusive education by aggregating the role of community. Hyde and Power (2004) argue that inclusion cannot be limited to the classroom environment, but students with disabilities need to be part of a wider school community; their results suggest that they might have got better grades, but they have not achieved social participation and individual independence. Similarly, Cole (2005) argues that an inclusive school requires multiple agencies: diversity within the student population, staff professional development, support of external agencies, cooperation among schools, parent involvement, community support, head teacher and senior management team commitment, classroom organization, and teaching assistant involvement. Into this multi-role community, Comer (2004) highlights the role of the teacher because it is the most involved on how to put policies into practice. Nonetheless, not only students with disabilities require inclusive policies, but that other minorities as well. Butcher et al. (2007) identified bilingual students as a problem in UK schools, while ignoring the positive attributes they bring to school from their home and culture. The authors suggest a threefold definition of inclusion: tolerance to mistakes, diversity of people, and equality of opportunities. Vincent and Thomson (2010) extend the excluded groups by considering pregnant school students. Thus, the UNESCO 'Policy guidelines on inclusion in education' (UNESCO 2009) focused on students with disabilities, ethnic and linguistic minorities as well as those affected by AIDS. The document promotes high quality education regardless of race, sexual orientation, religious beliefs, or socio-economic status.

More recent research on inclusive education reveals the dynamic character of inclusion as a social construction or deconstruction. Blandford (2013) argues that, beyond policies, inclusion is community involvement; thus, inclusion requires a social construction of different actors such as school management staff, teachers, parents and students as a community, but interaction among schools to share knowledge and experiences is also needed. Conversely, Haycock and Smith (2010) argue social deconstruction is needed if inclusion leads to undesirable consequences. Their study in UK high schools explained how teachers of physical education struggled to manage children with disabilities into the national curriculum, with negative consequences for teachers, mainstream students, and students with disabilities. Thus, failed cases of inclusion contribute to having a holistic perspective to understand inclusion benefits, but also inclusion risks and eventual deconstructions.

Thus, previous research insinuates that inclusion as a social construction or deconstruction requires a more practical knowledge, suggesting further research could study the connections 
and disconnections between inclusion and practice. This appears to be more relevant in developing countries. The review by Srivastava et al. (2015) on inclusive education in 140 developing countries of Africa and Asia revealed a gap between policy and practice. In spite of the adoption of international policies of inclusive education, only 16 countries were developing projects of inclusion for students with disabilities in mainstream schools. Figure 2 suggests stakeholders and associated practices involved in inclusive education.

Figure 2: Stakeholders and practices of inclusive education

Adaptable regulation

Necessary infrastructure

External agencies support

Reduce gap policy-practice

Extend to developing countries

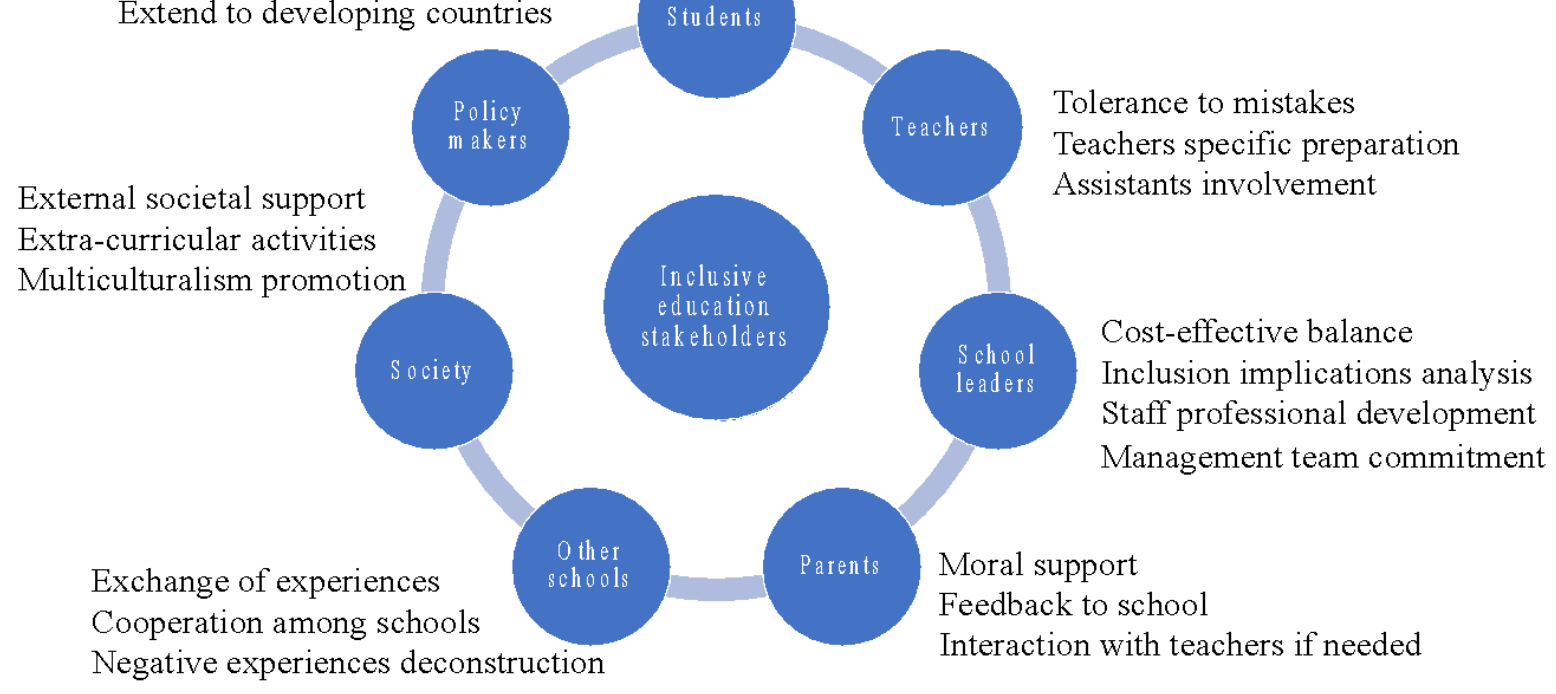

Source: Authors

\subsection{Inclusive education in Panaca: a process of social pedagogy}

Most research on inclusive education has an implicit legitimacy of those to be included. However, this inclusion initiative might be questioned, as those to be included are excombatants from illegal groups. It means that inclusion enters the field of moral acceptance. It can be understood as accepting others within the same group in spite of former actions.

One of the first authors who proposed the notion of social pedagogy underlined the relevance of "social conditions of culture and the cultural conditions of social life" (Natorp, 2001, P. 178). In quotidian life, social relationship passes not only through acquiring technical skills and operative processes, but assuming customs, traditions and social habits as well (Fermoso, 1994). These aspects of social life constitute forms of language (Willmann, 1921) that somehow indicate "belonging" to a particular culture: socialisation (Rodríguez, 2006). Some of the elements found in Panaca's socialisation process were: literacy, formalities within social processes and solidarity. 


\section{Method}

In order to capture how inclusive education contributed to inclusion of former combatants in Panaca operations, a series of open-ended (Rapley, 2001) and semi-structured interviews (Whiting, 2008) have been done. In total, 6 interviews and one focus group were performed; 3 of the interviews with management and operational staff and 3 with former combatants. It all happened in the context of Panaca park and Panaca foundation, a NGO that conducted an initial process of training to the former combatants in subjects such as customer service, organisational culture and communication skills. Another five interviews with former combatants allowed to capture how these policies and intentions from Panaca staff have been perceived by the reincorporated.

Interviews contributed to unpack some of the struggles and key factors of success that facilitated their inclusion into a labour context. of socialisation process of people that did not pass through formal education, and inclusive education manifested along the socialisation process

As all the interviews have been done in Spanish, the most common native language in Colombia, we needed to translate the responses to English. We made an initial translation, which later on was revised by a native speaker in both languages in order to ensure the meaning of the response correspond to the actual answer. Moreover, as the researchers are native Colombians, they are used to the meaning of colloquial expressions and subtle language.

All interviews were transcribed and coded. Coding was inductive as codes emerged from data collected (Bryman, 2016). Five codes synthetized the most relevant forms of inclusive education: socialisation, social pedagogy, learning formalities of labour work, and solidarity.

\section{Results}

\subsection{Socialisation}

The first manifestation of inclusive education was through communication. At the beginning of the reincorporation process the former combatants were taught to develop communication skills, but also to develop a sense of self-confidence: "In their education as human beings, they learned about empowering, so they developed communication skills and even most important, to trust themselves again and be able to trust in others" [Panaca management staff]. Even the first steps of contact and interaction with other people different from their former context contributed to change their identity: "Just to make eye contact forced them to dialogue and be not an ex-combatant, but just another Colombian". The communication workshops were essential to transform shy personalities into showmen: "When they (ex-combatants) arrived, in the first days they loon downwards, they didn't look at you because they seem to have fear. After our activities to promote trust, they were able to look in the eye, pick up a microphone, speak to an audience, and socialise with anyone" [Panaca foundation teacher]. Daily socialisation through informal communication was also essential for gaining confidence and integrating the former combatants into the normal life of Panaca. The manager of the park 
explained how does it worked: "We realised how they integrate faster if they are among other people. An educational process begins when they are not treated with stigmas or labels, but as equals. Only then, they felt included ... The casual contact with tourists asking Where is the toilet? forced them to employ a new language and to make them feel as a part of the park, creating a new identity" [Panaca park manager]. Then, socialisation as the development of communication skills in theory and practice contributed as a discursive first learning of inclusive education.

Socialisation also manifested by sharing the same formal and informal routines with other type of people, different than their group of ex-combatants, making them feel as part of the same team: "There were not any special treatment" [Panaca park supervisor]. "Suddenly they are all together, the environment propitiates such special integration" [Panaca foundation manager]. Socialisation extended beyond working schedules, which facilitated the feeling of inclusion: "They are where we are, we live in the same place, sharing similar beds and food; this detail enhances affection links between us. If someone got sick I'm beside the nurse". This kind of forced inclusion initiatives complemented with other emergent that comes from the daily routines that ex-combatants are immersed: "Now I don't spend too much of my time sharing with my partners from the reincorporation process, I have learned to share with other type of people" [ex-combatant]. Informal interaction with tourists also contributed to their socialisation: "Tourists were quite helpful in their reintegration process because they are used to ask several questions: what race is this horse? How often do they eat? How many rounds can I do? And so on, so they (the ex-combatants) are forced to talk and interact" [Panaca park supervisor].

At the beginning of the reincorporation process some tourists asked for the formers guerrillas as if they were a tourist attraction: "Who are they? Where they are? However, as they were melted with the rest they were everywhere, they had been included as any other person of the park" [Panaca park manager]. Inclusion tends to manifest when those included are hardly distinguished into the group they are included.

\subsection{Literacy}

Inclusive education presents additional challenges when students are illiterate, particularly if they are adults, which have some knowledge of combat and peasant labours, but none or scarce formal education in classroom: "Our director realised there is no inclusive education for illiterate peasants. Typically, technical education requires some writing and reading. Many of them don't know how to write or read, but they do know their farm labour and we just helped them to do it better" [Panaca foundation teacher].

As literacy process for adults takes a long time, the focus was to understand their farm skills and give them value in order to involve the group into the empirical knowledge the park offers to its visitors: "Most of our leisure activities involve experiential education, which will help you to solve something for real life" [Panaca park manager]. Although the central idea was just to help them (the ex-combatants) to improve their labour, some literacy was needed, not only 
for reinforce their knowledge, but to help them to increase their skills for life: "we needed to reinforce literacy at night" [Panaca foundation teacher]. Consequently, as some literacy was undertaken, the empirical knowledge of ex-combatants received a relevant value in order to involve them into the educational labour of the park.

\subsection{Mantaining formalities within social processes}

Inclusive education also manifested by learning the formalities and processes of the process in which they participated. In the training phase, it meant to share the same spaces and routines with people belonging to different spheres [ámbito (Rodríguez, 2006)], including former policemen; it took them to phase tension situations and solve them along the relation building.

Regarding the labour phase, the ex-combatants have never passed by a recruitment process, a learning they would needed to know in order to succeed as normal workers: "They had to pass all the recruitment process and present an interview. Not just because they were former combatants we would incorporate them directly, they needed to do all the process" [Panaca park HR manager]. Recruitment process remain the same in order to teach the ex-combatants all steps needed to access labour market. Likewise the normal processes to operate the park did not change: "The processes inside the park remain the same" [Panaca park manager].

To be included into the park routines was also a learning as it meant that the "new workers" had to adjust to schedules, duties, and responsibilities: "I have learned more about punctuality, rules, and timetables. For example, to be punctual does not mean to arrive on time, it means to have ready the horses on time for the customers at the time scheduled". They also needed to learn additional skills rather than increasing communication skills and improving farm labours. As they became another worker in a theme park they required to learn sales skills: "we did with them customer service workshops and sales clinics". New roles implied new learnings that formed into the ex-combatants a new identity.

\subsection{Solidarity}

Social pedagogy results in special manifestations of socialisation, which include soft skills. Close coexistence (Rodríguez, 2006) helps to develop friendships and solidarity attitudes. For example, one of Panaca's foundation manager told a story of one ex-combatant that had celebrated his birthday, something that he had never got before. He had a pink backpack and he used to receive some jokes for the colour of his backpck; the teacher explained: "As his birthday was approaching we decided to buy a more masculine backpack as a present and prepare a cake. When he came into the house and he saw all celebrations we prepared for him, he broke down in sobbing and weeping because he had never had a birthday party since 32 years when he was a kid" [Panaca foundation manager]. As those emotions have never been expressed clearly, this event unleashed a plenty of small celebrations in order to maximize the happiness of any small event: "We celebrated every small step of their lives, to have a bed, a purchase of a bike, even a purchase of a pot, all small celebrations were happiness for most of them". The initial step came from the Panaca workers, but they also understood that solidarity in the world of the ex- 
combatants might become even stronger: "If there is something I admire on them is their solidarity. If the salary was delayed they said: I can borrow you some money or here you have something. If they only have a tortilla to share is for all of them, they cooperate impressively". Small steps as a birthday celebration stimulated a big sense of solidarity that created a snowball effect of multiple other celebrations, strengthening labour and personal relations, indistinctly of their background. Therefore, inclusive education manifested as many formal and informal ways, both during labour duties, interaction between people from different backgrounds, different skills building workshops, and small celebrations in spirit of solidarity.

\section{Discussion and Conclusions}

Results suggested four manifestations of inclusive education: socialisation, social pedagogy, learning formalities of labour work and solidarity. Although the context is quite unique, due to the type of people integrated and the particular case, there are multiple contributions that may be applied to other contexts of inclusive education.

The case demonstrated to be effective, both in the plans undertaken from managers as well as from the emergent initiatives from grassroots, contributing to the debate that question the relative effectiveness of inclusion programmes and their costs associated (Murphy, 1996). Results also build Booth and Ainscow (2002) 'index for inclusion' in two dimensions: first, inclusive cultures, as the sense of community was essential to generate inclusion feelings; second, inclusive practices, as organisational resources needed to be mobilised in terms of people, training, extra-curricular activities, and workshops.

Community involvement was essential to facilitate inclusion. In the context of the case they were management staff, teachers, co-workers, and customers. Likewise inclusive education there are multiple stakeholders involved (Hyde and Power, 2004; Cole, 2005), but as education happened into a labour context, inclusion stakeholders involved organisational actors more than school actors. Nevertheless the main role both in schools or enterprises lays on the teacher as the main facilitator and the person that lead the activities to stimulate the feelings of inclusion in the people of the group included.

The results demonstrated that communication was the most relevant skill to be developed for inclusion. Communication began with initial exercises of looking at someone eye and be able to interact with people from other contexts into the workshops. Later on, the people included were able to interact with customers, co-workers and supervisors into the basic routines, instructions and respond to some basic questions. Finally, the people included were able to speak in public, lead activities and empower themselves. The transit from shyness to showmen was not automatically, several formal and informal educational activities were needed to achieve communicational skills, but it was essential to empower the people included and make them comfortable to their communication and feelings as part of the organisational context.

The results also suggest a definite value in terms of extra-curricular activities outside the normal work. Although marketing clinics, communication workshops, on the job training, and hard skills improvement, definitely contributed to facilitate inclusion and apprehend new learnings 
for succeeding and feeling included, the small celebrations seem to have been the key to create personal feelings of inclusion and stimulated new learnings about interpersonal skills such as motivation and empathy as well as intrapersonal skills such as self-value and self-awareness.

Limitations of this research are based in the particular context it happened. Further research might explore how has been inclusion of the same ex-combatants not in operational tasks but into administrative tasks. In addition as there are plenty of other conflicts worldwide, it would be helpful to know how inclusion of former combatants have happened in other countries, and to distinguish similarities and differences; as Blandford (2013) suggests, interaction and sharing of best practices of inclusion is essential for its successful implementation. There are illegal groups from far right and others of far left, it would be interesting how inclusion works among opposite ideologies. In any case, the results from this paper shed some light on how to include adults into labour contexts through inclusive education programs. In addition, this research contributes to multiple governments and organisations interested to include the millions that come from disadvantaged situations, which have remained out of formal education.

\section{References}

Blandford, S. (2013). The impact of 'Achievement for all' on school leadership. Educational Management Administration and Leadership, 41, pp. 45-62.

Bryman, A. (2016). Social research methods. Oxford University Press, Oxford, UK.

Butcher, J., Sinka, I. and Troman, G. (2007). Exploring diversity: teacher education policy and bilingualism. Research Papers in Education, 22 (4), pp. 483-501.

Cole, B. A. (2005). Mission impossible? Special educational needs, inclusion and the reconceptualization of the role of the SENCO in England and Wales. European Journal of Special Needs Education, 20(3), 287-307.

Comer, C. (2004). 'What's he done today?' supporting teachers of children with emotional and behavioural difficulties in mainstream classrooms. Teacher Development, 8 (2), pp. 313-323.

Dobusch , L., Dobusch, L., \& Kreissl, K. (2017). Approaching the "Good Organization": Comparing Open, Inclusive and Alternative Organizations. EGOS 2017 Sub-theme 12: Being Good or Looking Good? Interrogating the Contradictions and Tensions in Organizational Ethics. Cpenhagen, Denmark: European Group for Organization Studies.

Farndale, E., Biron, M., Briscoe, D. and Raghuram, S. (2015). A global perspective on diversity and inclusion in work organisations. The International Journal of Human Resource Management, 26 (6), pp. 677-687.

Ferdman, B. (2014). The Practice of Inclusion in Diverse Organizations. In F. B.M., \& B. Deane, Diversity at Work: The Practice of Inclusion, pp. 3-54). San Francisco (CA): JosseyBass.

Fermoso, P (1994); Pedagogía Social. Fundamentación científica. Barcelona: Editorial Herder. 
Florian, L., \& Linklater, H. (2010). Preparing teachers for inclusive education: using inclusive pedagogy to enhance teaching and learning for all. Cambridge Journal of Education, 40(4), 369-386.

Frederickson, N., Dunsmuir, S., Lang, J., \& Monsen, J. (2004). Mainstream-Special School Inclusion Partnerships: Pupil, Parent and Teacher Perspectives. International Journal of Inclusive Education, 8(1), 37-57.

Gurung, H. (2006). From exclusion to inclusion: socio-political agenda for Nepal. Social inclusion Research Fund. Kathmandu, Nepal. ISBN 9994696866.

Hunold, C. (2005). Green political theory and the European Union: The case of a non-integrated civil society, Environmental Politics, 14 (3), pp. 324-343.

Hyde, M. and D. Power (2004). Inclusion of deaf students: An examination of definitions of inclusion in relation to findings of a recent Australian study of deaf students in regular classes, Deafness \& Education International, 6, pp. 82-99.

Karangwa, E. (2006). Grassroots community-based inclusive education. Exploring educational prospects for young people with disabilities in the post-conflict Rwandan communities.

Katholieke Universiteit Leuven, Faculteit Psychologie en Pedagogische Wetenschappen. Leuven, Belgium: Centre for Disability, Special Needs Education and Child Care.

Lako, C. L., Van der Linden, J., \& Deng, W. (2010). South Sudan Inclusive: Education in WarTorn Area. In J. Zeelen, D. Nampota, J. Van der Linden , \& M. Ngabirano, The Burden of Educational Exclusion (págs. 141-155). Utrecht, The Netherlands: Brill Sense.

Landorf, C. (2011). Evaluating social sustainability in historic urban environments. International Journal of Heritage Studies, 17 (5), pp. 463-477.

McConkey, R., \& Bradley, A. (2010). Promoting inclusive education in low-income countries. In V. Timmons, \& P. N. Walsh, A long walk to school: global perspectives on inclusive education. Rotterdam, The Netherlands: International Association for the Scientific Study of Intellectual Disabilities.

Mittler, P. (2007). Education - The Missing Link at Transition. Tizard Learning Disability Review, 12(2), 14-21.

Murphy, D. M. (1996). Implications of inclusion for general and special education, The Elementary School Journal, 96, pp. 469-493.

Natorp, P. (2001). Pedagogía social. Teoría de la educación de la voluntad sobre la base de la comunidad. Madrid: Editorial Biblioteca Nueva.

OECD. (2003). Education policy analysis. Organization for Cooperation and Development. Paris: Centre for Educational Research and Innovation, OECD Education and Skills.

Rapley, T. (2001). The art (fulness) of open-ended interviewing: some considerations on analysing interviews. Qualitative Research, 1(3), pp. 303-323.

Ryan, D. (1994). Inclusion: the key to success. Proceedings of the annual national conference of the American council on rural space education. Austin, Texas. 


\section{AREIL}

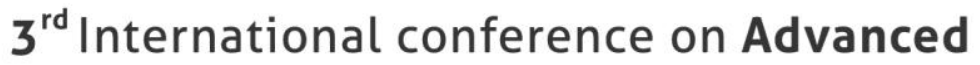
Research in Education, Teaching \& Learning

Rodríguez, A (2006); Hacia una fundamentación epistemológica de la pedagogía social; In Educación y educadores; 9(2), 131-147.

Savolainen, H., Engelbrecht, P., Nel, M., \& Malinen, O.-P. (2012). Understanding teachers' attitudes and selfefficacy in inclusive education: implications for pre-service and in-service teacher education. European Journal of Special Needs Education, 27(1), 51-68.

Siddiqui, M. A. (2007). Inclusive education for street children in India. In G. Verma, C. Bagley, \& M. Jha, International perspectives on educational diversity and inclusion: studies from Aamerica, Europe and India (págs. 162-180). New York: Routledge.

Srivastava, M., de Boer, A., \& Pijl, S. (2015). Inclusive education in developing countries: a closer look at its implementation in the last 10 years. Educational Review, 67(2), 179-195.

UNESCO. (1994). Salamanca Statement on Principles, Policies and Practice in Special Needs Education. World Conference on Special Needs Education: Access and Quality. Salamanca, Spain: UNESCO.

UNESCO. (2000). Dakar Framework for Action: Expanded Summary Education for All. World Education Forum. Dakar, Senegal: UNESCO.

UNESCO. (2009). Policy guidelines on inclusion in education. Paris: UNESCO.

Vincent, K. and Thomson, P. (2010). 'Slappers like you don't belong in this school': the educational inclusion/exclusion of pregnant schoolgirls. International Journal of Inclusion Education, 14 (4), pp. 371-385.

Wang, Y., \& Mu, G. M. (2014). Revisiting the Trajectories of Special Teacher Education in China through Policy and Practice. International Journal of Disability, Development and Education, 61(4), pp. 346-361.

Whitting, L. (2008). Semi-structured interviews: guidance for novice researchers. Nursing Standard, 23, pp. 35-40.

Willmann, O (1921). The science of education in its sociological and historical aspects; Leopold Classic Library. 